\title{
RESEARCH
}

Open Access

\section{Treatment of vocal fold scarring with autologous bone marrow-derived human mesenchymal stromal cells-first phase I/II human clinical study}

Stellan Hertegård ${ }^{1,2^{*}}$, Srinivasa Rau Nagubothu ${ }^{3}$, Emma Malmström ${ }^{1,2}$ and Katarina LeBlanc $c^{3,4}$

\begin{abstract}
Background: Vocal fold (VF) scarring, caused by surgery or inflammation, often results in severe voice problems or aphonia. Effective lasting treatment is lacking. Previous in vitro and in vivo animal studies reported positive effects on VF scar resolution with mesenchymal stromal cell (MSC) implantation. The principal aim of this study was to examine safety aspects and secondly treatment efficacy vocal fold function in patients with VF scarring and severe voice problems.
\end{abstract}

Methods: In this open-label phase I/II study, 16 patients were treated with surgical scar resection followed by injection of autologous MSCs (0.5-2 $\times 10^{6} \mathrm{MSCs} /$ patient). Patients were monitored 1 year for serious adverse events (SAE) or minor complications. Therapeutic efficacy on treated VFs was evaluated by measurement of VF vibrations using high-speed laryngoscopy (HSL) and phonation pressure threshold (PTP) for elasticity and VF function. Patients self-reported voice change using the Voice Handicap Index (VHI).

Results: No SAE or minor side effects were reported. Video ratings of VF vibrations and digitized analysis of HSL and PTP were significantly improved for $62-75 \%$ of the patients (depending on parameter). Two patients showed deteriorated VF vibrations, but improved PTP. VHI was significantly improved in 8 patients, with the remaining experiencing no significant change.

Conclusions: The results indicate that local injection of autologous MSC into scarred VFs with severe voice problems may offer a safe and feasible therapeutic option. VF vibration and elasticity were improved in approximately two thirds of treated patients.

This clinical study is registered in clinicaltrials.gov (ID: NCT01981330). Retrospective registration of first patient (20130511). https//: register.clinicaltrials.gov/.

Keywords: Vocal fold, Scarring, Hoarseness, Mesenchymal stromal cells, Fibrosis, Immunomodulation, Wound healing

\footnotetext{
* Correspondence: Stellan.Hertegard@ki.se

'Department of Clinical Sciences and Intervention, Karolinska Institutet, Stockholm, Sweden

${ }^{2}$ Department of Otorhinolaryngology, Karolinska University Hospital Huddinge, S-141 86 Stockholm, Sweden

Full list of author information is available at the end of the article
}

(C) The Author(s). 2020 Open Access This article is licensed under a Creative Commons Attribution 4.0 International License, which permits use, sharing, adaptation, distribution and reproduction in any medium or format, as long as you give appropriate credit to the original author(s) and the source, provide a link to the Creative Commons licence, and indicate if changes were made. The images or other third party material in this article are included in the article's Creative Commons licence, unless indicated otherwise in a credit line to the material. If material is not included in the article's Creative Commons licence and your intended use is not permitted by statutory regulation or exceeds the permitted use, you will need to obtain permission directly from the copyright holder. To view a copy of this licence, visit http://creativecommons.org/licenses/by/4.0/ The Creative Commons Public Domain Dedication waiver (http://creativecommons.org/publicdomain/zero/1.0/) applies to the data made available in this article, unless otherwise stated in a credit line to the data. 


\section{Background}

Voice problems occur in about $9 \%$ of the Western population causing communicative and occupational problems or unemployment, resulting in estimated health costs exceeding 11 billion US dollars [1, 2]. Vocal fold (VF) mucosal damage is evident in $60-80 \%$ of patients seeking medical help [3]. VF scarring is considered the most common cause of severe voice problem manifesting with severe dysphonia or aphonia, strained phonation, and reduced VF vibrations [4]. Voice therapy for VF scarring is usually ineffective, as well as surgery, which may even worsen the condition $[1,4]$.

Numerous approaches have been utilized to improve VF function after scarring. Bioimplant injections (for example fat and hyaluronan; HA) to fill out the VF defect and soften the tissue demonstrated some improvement in VF function $[5,6]$. Likewise, injection of growth factors such as hepatocyte and basic fibroblast growth factors were examined in in vivo and clinical trials, with positive outcomes [7, 8]. Injection of autologous fibroblast in 5 humans with VD scar showed improved mucosal waves as well as VHI and voice quality [9]. However, currently, there is no longlasting effective treatment for VF scarring.

Mesenchymal stromal cells (MSC) have antiinflammatory properties. In vitro studies have demonstrated that MSCs suppress $\mathrm{T}$ cell responses, inducing a regulatory phenotype, skewing the innate immune system, and promoting an anti-inflammatory milieu [10, 11]. Adoptive transfer of MSCs, in clinical trials, demonstrated promising results in reversing conditions, such as therapy-refractory graft-versus-host disease and acute respiratory distress syndrome $[12,13]$. How MSCs mediate an immunosuppressive function has not been fully elucidated, but appears to include release of paracrine mediators modulating cells within the local environment. Despite low-level engraftment of transplanted MSCs [14], they induce long-term effects within the body via their "hit and run" actions, reducing tissue damage and promoting endogenous healing $[11,15]$.

Numerous pre-clinical in vivo models to evaluate the effects of local administration of MSCs into scarred VFs have been reported, each suggesting positive effects on wound healing and regeneration of inherent VF characteristics and functionality [16-18]. Our own in vivo model in rabbits demonstrated both short- and long-term effects of MSC injection on VF tissue inflammation, architecture, and function [19-22]. Despite lowlevel persistence of the MSCs within the injury site, long-term effects were seen on matrix composition and tissue architecture, with lowered type I collagen content, reduced lamina propria (LP) thickening, and normalized histology compared to untreated injured controls [1922]. Viscoelastic parameters, from rheometry, demonstrated a significant improvement in tissue functionality after MSC treatment [19, 20]. Resection of established VF scar followed by MSC injection gave the same result
[21]. Investigation into MSC mode of action within these studies showed that MSCs significantly expedite resolution of acute phase inflammation within the injured tissue (equivalent to scar tissue resection within the clinical context). Acute phase pro-inflammatory cyto/chemokines including interleukin (IL)-1b and IL-8 were reduced within MSC-treated VFs and increased levels of CD163+ anti-inflammatory macrophages within 2-4 days after damage [22].

Our preclinical testing demonstrated the safety of MSC injection into the VF, with no side effects evidenced [18-22]. We have furthermore confirmed the safety and effectiveness of delivering MSCs within HA hydrogel in vivo. These findings provided us with data supporting that HA could be safely used as a delivery vehicle where defects were of a critical size, providing a scaffold for the MSCs [23].

Limited studies have been undertaken in man, with a case study recently reporting positive results 1 year after treating a female patient presenting with VF scarring and hoarseness, with injection of autologous adiposederived stromal vascular fraction (SVF) [24].

\section{Methods}

Aim

We aimed with this phase I/II study to evaluate the safety and therapeutic potential for MSC treatment in humans with manifest VF scarring to restore vocal fold function.

\section{Patients}

Ethical permissions (DNR 2010/1650 and DNR 2014/ 51432) were received from the Stockholm regional ethical review committee. The study design was identical in both permissions with one treatment arm for patients treated with MSC only and another treatment arm where MSC was mixed with a HA gel. The first permission was for the treatment of 8 patients and the second for a continued study including more patients (in total 16, see VF surgery). The study was registered in registration @clinicaltrials.gov (ID: NCT01981330). Patients provided written informed consent before the procedure. The inclusion and noninclusion criteria are summarized in Table 1. Sixteen patients were included (Table 2). The mean age of the patients was 54 years (30-74 years, 11 males and 5 females). No female patient was pregnant, and all patients were negative for HIV, HBV, HCV, HTLV, syphilis, and lues. Patients were diagnosed using videostroboscopic examination or a high-speed camera by an experienced phoniatrician and later confirmed with direct microlaryngoscopy. All patients had manifest symptoms ( $\geq 3$ years), strained voice, and severe dysphonia. Seven patients had unilateral scar, 9 bilateral, and 5 patients had larger tissue defects (at least $1.5-2 \mathrm{~mm}$ glottal closure width defect during phonation). Scarring was caused by previous ( $>3$ years ago) VF 
Table 1 Inclusion and non-inclusion criteria for the clinical trial: MSC treatment of vocal fold scarring

Inclusion criteria
Severe hoarseness, vocal fatigue
Vocal fold scarring
No active other treatment
Age above 18 years
Exclusion criteria
Active treatment of laryngeal disorder
Active inflammatory condition of the larynx or laryngeal papilloma
Diagnosed or suspicions of local malignancy
No female patient was pregnant and all patients were negative for
HIV, HBV, HCV, HTLV, syphilis, and lues

surgery or trauma $(n=6)$, surgery due to laryngeal cancer with $(n=2)$ and without $(n=1)$ radiation therapy (15 years previous). In 6 patients, scarring was combined with sulcus vocalis, and for 1 patient, the etiology was unknown (P5). All patients were previously treated with voice therapy (at least 5-10 sessions) by a speech and language pathologist without improvement. Six patients had been treated with pure HA injections into one VF $>2$ years previously, however with no or short-term improvement.

\section{Isolation and characterization of bone marrow MSCs}

The MSC expansion procedure was accredited by the Swedish National Board of Health and Welfare (952/2009, 6.3.3-8874/2011, 6.1.3-9791/2013, 6.1.3-16411/201). Autologous MSCs were isolated from the iliac crest for each patient as previously described [25]. Expansion and characterization of MSCs was performed according to guidelines of the European Blood and Marrow Transplantation Group approved by the Swedish National Board of Health and Welfare. Bone marrow mononuclear cells were seeded at a density of $1.6 \times 10^{5}$ cells $/ \mathrm{cm}^{2}$ in Dulbecco's modified Eagle's medium-low glucose supplemented with platelet lysate (final concentration equivalent of $9 \times 10^{7}$ platelets $/ \mathrm{ml}$ ). Platelet concentrate was purchased from the Department of Transfusion Medicine, Karolinska University Hospital, Huddinge, Sweden. At 80-90\% confluency, cells were detached with TrypLE ${ }^{\text {тм }}$ (Invitrogen, NY, USA) and replated at 3.0-4.0 $\times 10^{3}$ cells/ $\mathrm{cm}^{2}$ for one passage. Cells were cryopreserved in complete cell culture media supplemented with $10 \%$ (v/v) dimethyl sulfoxide (DMSO; WAK-Chemie Medical GmbH, Steinbach, Germany). Before use, cells were washed in phosphate-buffered saline and resuspended in $0.9 \%(\mathrm{v} / \mathrm{v})$ saline solution supplemented with $10 \% \mathrm{AB} R \mathrm{Rh}+$ plasma at a concentration of $2.0 \times 10^{6} \mathrm{MSCs} / \mathrm{ml}$. Release criteria were based on the absence of visible clumps, spindleshaped morphology, absence of contamination by pathogens (bacteria and mycoplasma), and viability $>95 \%$. Flow cytometry confirmed an MSC surface profile as per the International Society for Cellular Therapy guidelines $\left(\mathrm{CD}_{3}{ }^{+}, \mathrm{CD} 0^{+}, \mathrm{CD} 105^{+}\right.$, human leukocyte antigen $[\mathrm{HLA}]-\mathrm{I}^{+}$and $\mathrm{CD}_{14}^{-}, \mathrm{CD}_{4}^{-}, \mathrm{CD}^{-}, \mathrm{CD}^{-} 0^{-}, \mathrm{CD}_{4} 5^{-}$ $\mathrm{HLA}^{-\mathrm{II}^{-}}$) [26]. All patients received MSCs at passage 1.

\section{Vocal fold surgery and MSC administration}

During microlaryngoscopy (Fig. 1), scar tissue was removed/reduced from the LP with minimal epithelium resection to create a fresh wound. Thirteen patients were operated unilaterally on the most scarred and stiffer VF, and 3 patients, where microlaryngoscopy showed severe or symmetrical bilateral scar, were operated bilaterally (P2, P5, P9). MSC injections $\left(0.5-1 \times 10^{6}\right.$ cells/damaged VF [total dosage $0.5-2 \times 10^{6} /$ patient dependent on the amount of VF damage and defect size]) were performed using a Medtronic Xomed 27G laryngeal injector into the LP and thyroarytenoid muscle in 8 patients. If leakage was noted at the beginning, the injection was adjusted until a dose of $0.5-1 \times 10^{6}$ cells/damaged VF was administered. No patient was excluded because of leakage. Cell dosage was based on previous animal safety data and adjusted for difference in membranous VF volume between humans and rabbits [19-23]. The ethical permissions also included a second treatment arm where MSC was mixed with a HA gel scaffold. We included 8 randomly chosen patients where the MSCs (cell dosage within the same ranges as above) were mixed with HA gel (Auxigel ${ }^{\mathrm{Tm}}$; Termira AB, Stockholm, Sweden, [23, 27]). The gel was prepared by mixing $0.9 \%(\mathrm{w} / \mathrm{v}) \mathrm{HA}$ in phosphate-buffered saline (PBS; part A) with $0.1 \%(\mathrm{w} / \mathrm{v})$ polyvinyl alcohol derivative in PBS (to induce crosslinking, part B) at a 3:1 ratio. The aim was to examine if the gel improved cell placement near the wound area and increased healing. All patients were recommended voice rest 5-7 days postoperatively. No antibiotics were given. Five patients declined postoperative voice treatment, with the remaining patients receiving 2-10 sessions. All patients were examined postoperatively at 1 week, $1,3,6$, and 12 months.

\section{Side effects and complications}

Patients were monitored during and following surgery (between $3 \mathrm{~h}$ for day care surgery and $24 \mathrm{~h}$ for overnight stay patients) and at each of the follow-up visits. The patients were interviewed and examined for side effects (SAE) including systemic reactions, airway problems, infections, tumor formation, and minor, local effects, e.g., fold edema, laryngitis VF hematoma, and granuloma.

\section{Analysis of vocal fold vibrations and phonation pressure threshold}

Functional vocal fold parameters were analyzed from: 


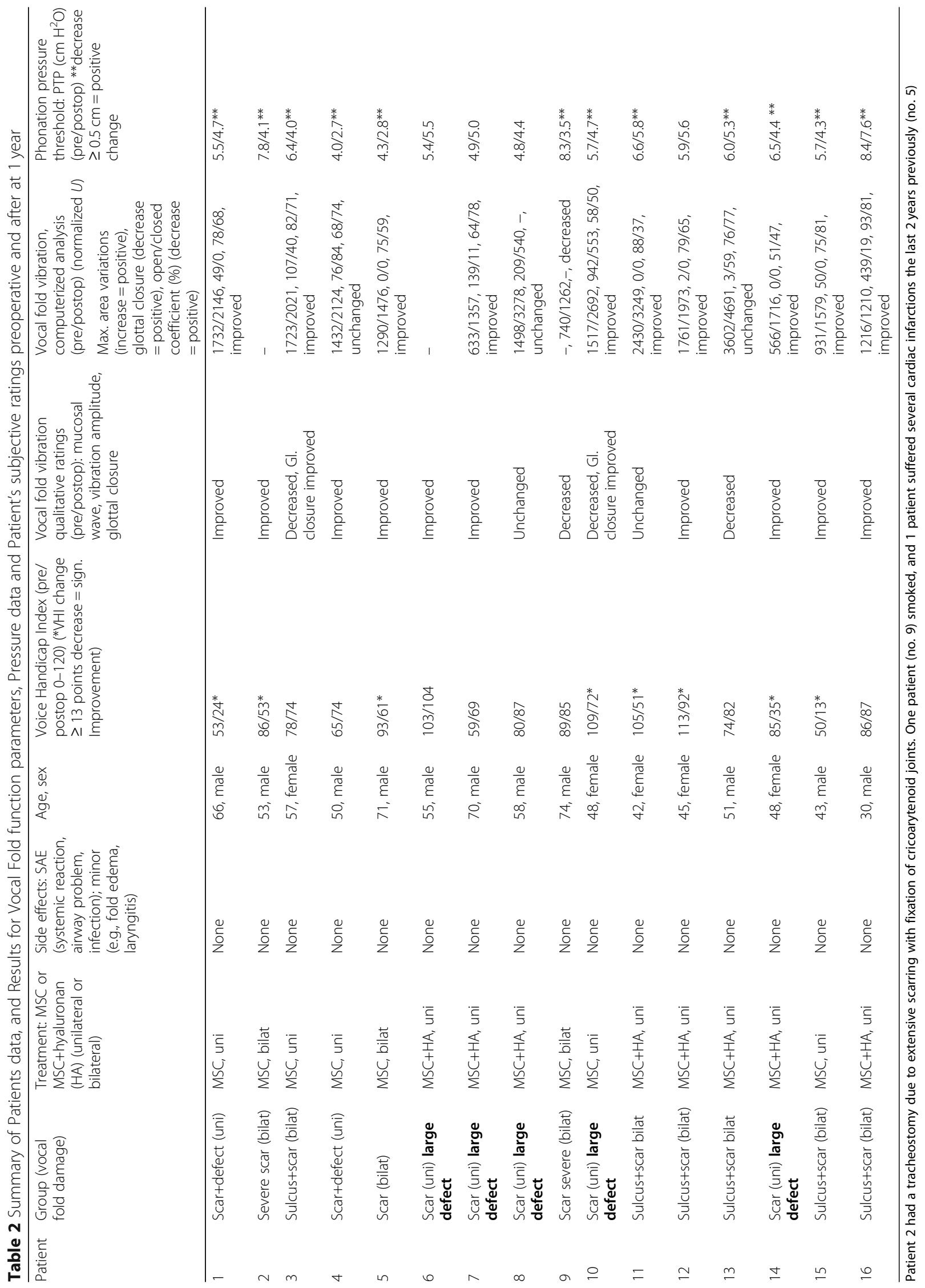



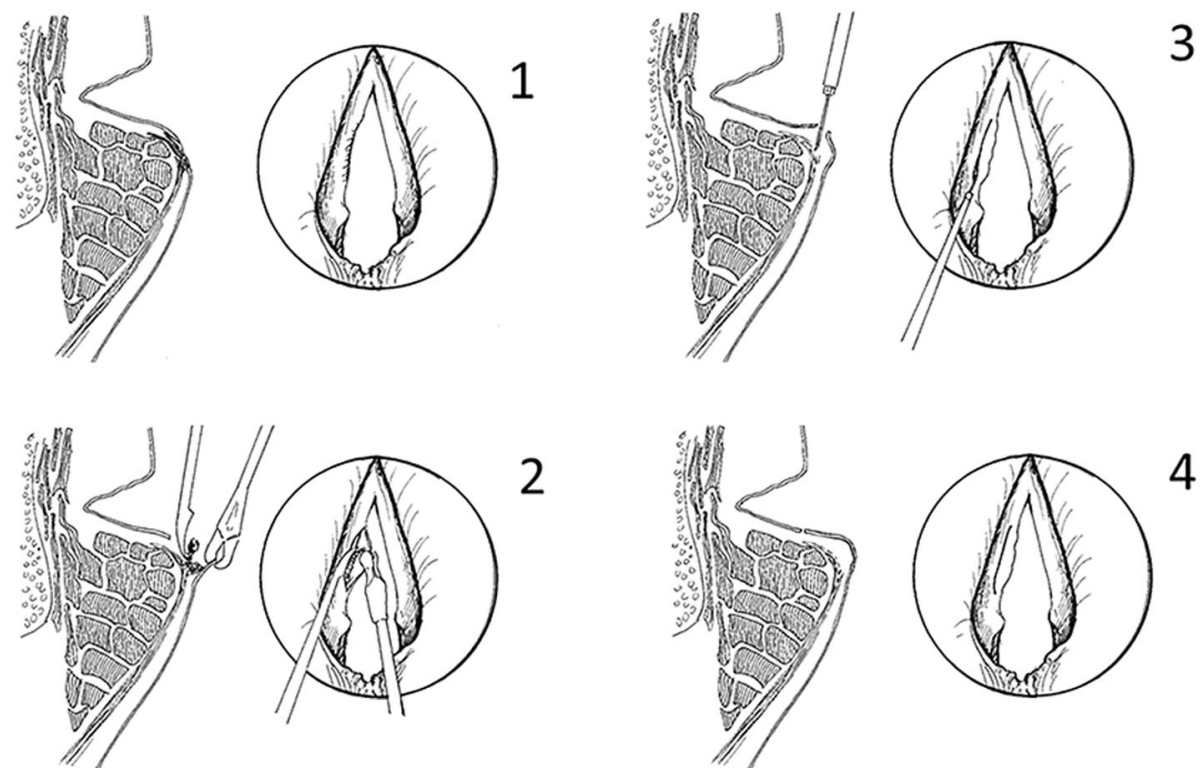

Fig. 1 Surgery. Schematic drawing of operative technique. 1 Preoperative status with scar at vocal fold edge. 2 After cordotomy with microflap technique, scar resection. $\mathbf{3}$ Injection of MSCs in lamina propria and superficial thyroarytenoid muscle (not shown in figure). $\mathbf{4}$ Directly after surgery

\section{High-speed examinations, videostroboscopic recordings}

Digitized high-speed recordings were made using a Hispec 1 camera with an image resolution set to $500 \times$ 250 pixels at 4000 images/s (Fastec Imaging, San Diego, USA) combined with a $300 \mathrm{~W}$ xenon light source (5131, Richard Wolf GmbH, Knittlingen, Germany). Videostroboscopy was performed with a Wolf stroboscope (5052) attached to a Wolf videocamera (5512). The video was digitized using FonMedia software (Hans Larsson, Karolinska Institutet). A $70^{\circ}$ rigid Karl Storz (Tuttlingen, Germany; 8700) laryngoscope or Olympus (ENF-P4) flexible laryngoscope was used for examination. Patients sustained an /ee/ like vowel at different intensities and pitches. The phonation with the best closure, closest to the habitual speaking pitch and intensity, was further analyzed.

\section{Subjective video ratings}

The recordings were mixed pairwise (pre- and postoperative) randomly adding $10 \%$ extra samples for intra-reliability testing of the judges. The judges were 3 experienced phoniatricians, without prior knowledge of the patient's diagnoses or treatment, who blindly rated the following VF parameters: glottal closure, amplitude of vibration, and mucosal wave. The judges rated the pre- and 1 year post-operative recordings pairwise in random order using the global categories A: best status, B: worse status, and C: unchanged/unclear. Ratings were made for high-speed recordings, except for P2 and P6 where videostroboscopic recordings were used.

\section{High-speed computerized analysis}

The high-speed recordings were analyzed using a specially developed software High-Speed Studio (HSS) [28]. Digitized images of glottal area variations during vibration were traced by automatic edge detection and normalized to the membranous VF portion length at the glottal midline (Figs. 2 and 3). Relative glottal area closure (minimum area) and relative maximum glottal area variations (vibrations) were calculated using Sopran (Tolvan Data, Stockholm, Sweden). The open/closed coefficient during vibratory cycles was calculated using HSS from kymograms (Fig. 2). This reflects the degree of glottal closure during phonation [28].

The phonation pressure threshold (PTP) was recorded as a measure of vocal onset effort and indirect estimation of glottal mucosal elasticity [29]. PTP was estimated from intraoral pressure during repeated "pa" syllables at habitual pitch and effort with decreasing intensity until phonation ceased. Pressure $\left(\mathrm{cm} \mathrm{H}^{2} \mathrm{O}\right)$ was recorded with a 4-mm diameter catheter placed in the corner of the patient's mouth connected to a log data recorder (Pico Technology, St. Neots UK; model 1012, Pico Scope software, v6). PTP was calculated from a mean of 3 pressure peaks surrounding vowels during stable syllable repetitions at the softest possible phonation. 


\section{a.}

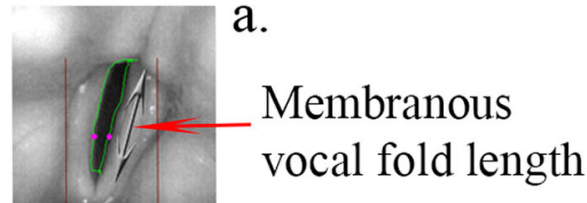

Opening Closing

b. phase phase
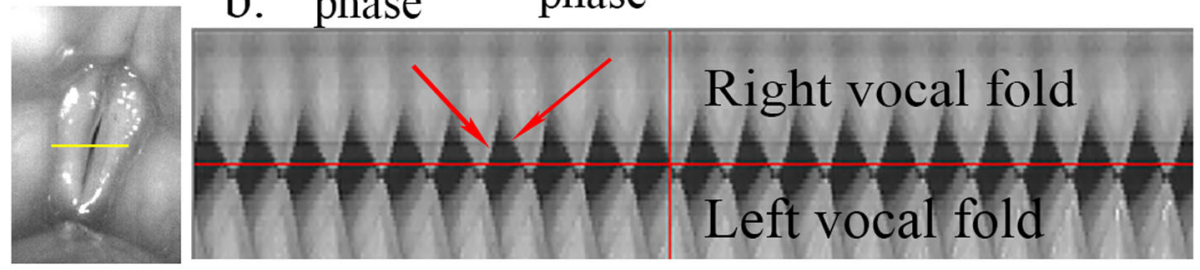

c.
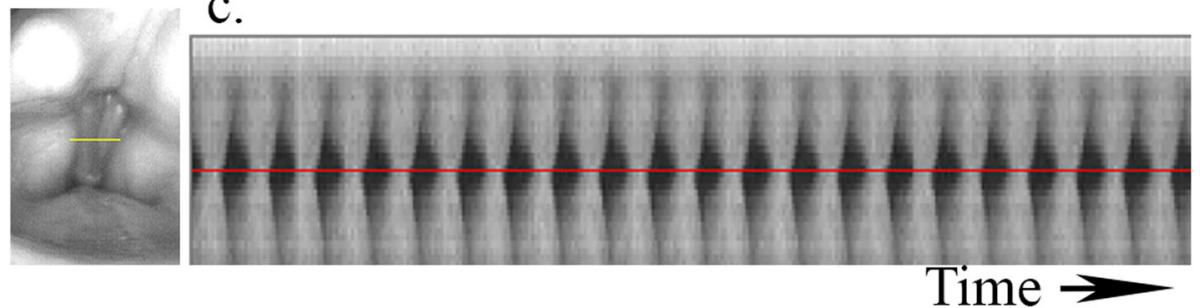

Fig. 2 Vocal fold analysis of high-speed laryngoscopy. a (Top) Edge tracking of glottal area during vibration. Dots at midpoint of left and right vocal folds. Arrow marks length of membranous vocal fold part use for normalization of vibration and glottal area. b (Mid) Preoperative recording. c (Bottom) Postoperative recording for patient 12 with corresponding kymograms from the horizontal yellow line plane (left). Right vocal fold vibrations are shown above and left local fold below. Red vertical line at preoperative kymogram corresponds to maximum glottal closure (left image). High-Speed Studio software automatically sets glottal midline (red horizontal) and analyzes the brighter pixels at the most closed phase during each vibratory cycle in relation to the darker pixels during the open phase. Open/closed coefficient is calculated from this relation. Preoperative $\mathrm{O} / \mathrm{C}$ coefficients in the figure are $73 \%$ preoperatively and $52 \%$ postoperatively indicating improved glottal closure. Preoperative, there is a time phase delay of maximum closure for the right vocal fold in comparison with the left vocal fold which is normalized after treatment of the right vocal fold

\section{Patient's subjective ratings}

The patients rated their voice symptoms using the Voice Handicap Index scale (VHI, Swedish version) including subscales reflecting functional, physical, and emotional aspects of voice [30].

\section{Statistics}

Analysis of patient data was performed using nonparametric methods: Wilcoxon paired sign rank test for pairwise comparisons (pre-operative and 1-year followup), Mann-Whitney $U$ test for group comparisons of rate of parameter changes between groups, and Binomial test (sign test) for analysis of video ratings. Significance level was set to $p<0.05$ (Statview 5.0; SAS Institute Inc., Cary, NC USA, Open version).

\section{Results}

\section{Side effects and complications}

No complications or SAEs were reported, e.g., local edema, bleeding, granuloma, tumor formation, or signs of infection during the observation time (Table 2).

\section{High-speed examination, videostroboscopic, and PTP analyses}

The intra- and inter-rater reliability for the qualitative video ratings was satisfactory (over $70 \%$ of the judgments fell in the same category for the doubled samples). Video ratings demonstrated improvement in 10 patients, with no evaluable change in further 2 patients. In 4 patients, VF vibrations decreased; however, for 2 individuals, glottal closure was improved, which is also important to voice production (Table 2). Taken together, 10 patients showed improvement, 2 decreased, and 4 unchanged based on video rating. Binomial sign test for 10 patients with improved and 4 with decreased vibrations resulted in $p=0.176$, and for 10 improved and 2 decreased, a significant improvement was found, $p=0.0386$ (Tables 2 and 3).

For the computerized analyses, no statistical difference was found for phonation frequency (F0) or sound pressure level (SPL) between preoperative and follow-up examinations. Vocal fold vibration data showed improvement (for at least 2 out of the 3 parameters analyzed) in 10 out of 14 patients, unchanged in 3 , and deterioration in 1 . The results from computerized analysis of the high-speed recordings 


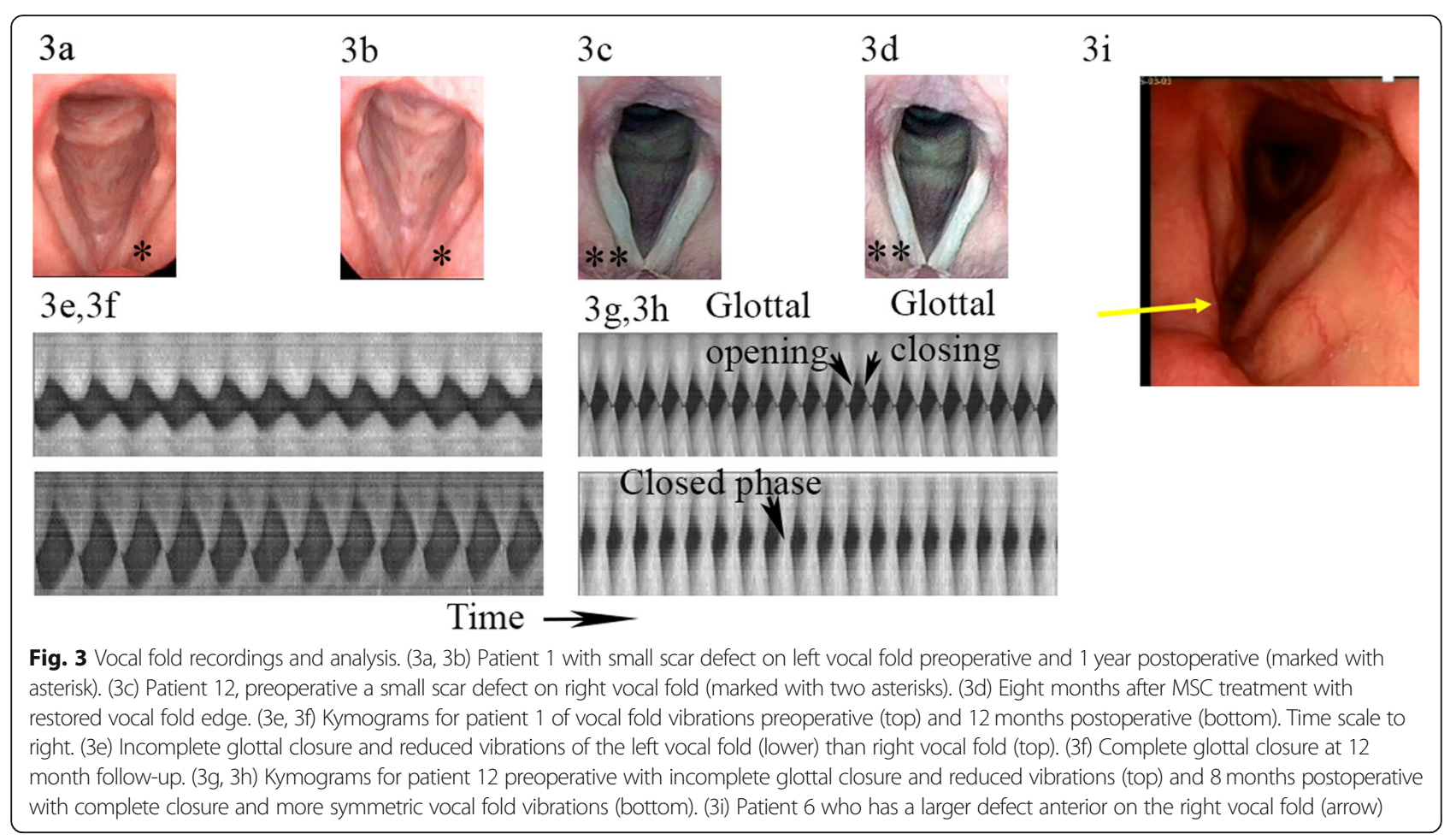

and for PTP before and 1 year after treatment are shown in Fig. 4. The pairwise comparisons show a clear improvement for the vibrations (glottal area variations) and for PTP, whereas the glottal closure measurements show a mixed result (minimum glottal area and open/closed coefficient).
The PTP parameter indirectly reflects VF elasticity. We found improvement (decrease $\geq 0.5 \mathrm{~cm} \mathrm{H}^{2} \mathrm{O}$ ) in 12 patients and no change in 4. Patients 9 and 13 who showed decreased or unchanged vibrations were both improved for the PTP (Table 2 and Fig. 4).

Table 3 Statistical evaluation of vocal fold function parameters

\begin{tabular}{|c|c|c|c|c|}
\hline Parameter & All patients $(n=16)$ & $\begin{array}{l}\text { Patients treated with MSC only } \\
(n=8) \text { or MSC+hyaluronan }(\mathrm{HA}) \\
(n=8)\end{array}$ & $\begin{array}{l}\text { Patients with smaller } \\
\text { defects }(n=11)\end{array}$ & $\begin{array}{l}\text { Patients with large } \\
\text { defects }(n=5)\end{array}$ \\
\hline $\begin{array}{l}\text { VHI (subjective voice } \\
\text { handicap scale) }\end{array}$ & $\begin{array}{l}\text { T0, } 83 \text { (SD 19); T1, } \\
66 \text { (SD 25) }(p=0.04)\end{array}$ & $\begin{array}{l}\text { MSC: T0,78 (SD 20.5); T1, } 57 \text { (SD } \\
\text { 25.7) }(p=0.036) \\
\text { MSC+HA: T0, } 88 \text { (SD 18); T1 } 76 \\
\text { (SD 23) ( } p=\text { ns) }\end{array}$ & $\begin{array}{l}\text { T0, } 81 \text { (SD 20); T1, } 63 \\
(\mathrm{SD} 26)(p=0.04)\end{array}$ & $\begin{array}{l}\text { T0, } 87 \text { (SD 20); T1,73 } \\
\text { (SD 26); ns }\end{array}$ \\
\hline $\begin{array}{l}\text { Phonation pressure } \\
\text { threshold, PTP }\left(\mathrm{cm} \mathrm{H}^{2} \mathrm{O}\right)\end{array}$ & $\begin{array}{l}\text { T0, } 6.0 \text { (SD 1.3); T1, } \\
4.7(\mathrm{SD} 1.2)(p=0.0008)\end{array}$ & $\begin{array}{l}\text { MSC: T0, } 6.0(\mathrm{SD} 1.5) ; \mathrm{T} 1,3.85 \\
(\mathrm{SD} 0.8)(p=0.01) \\
\text { MSC+HA: T0, } 6.1(\mathrm{SD} 1.15) ; \mathrm{T} 1 \\
5.45(\mathrm{SD} 1.0)(p=0.36)\end{array}$ & $\begin{array}{l}\text { T0, 6.2 (SD 1.5); T1, } 4.6 \\
\text { (SD 1.4) }(p=0.003)\end{array}$ & $\begin{array}{l}\text { T0, } 5.5 \text { (SD 0.7); T1, } 4.8 \\
\text { (SD 0.5); ns }\end{array}$ \\
\hline $\begin{array}{l}\text { Maximum amplitude of } \\
\text { glottal vibrations }(U)\end{array}$ & $\begin{array}{l}\text { T0, } 1551 \text { (SD 760); T1, } \\
2270 \text { (SD 982) }(p=0.0019)\end{array}$ & $\begin{array}{l}\text { MSC: T0,1430 (SD 275); T1, } 2006 \\
\text { (SD 440) }(p=0.03) \\
\text { MSC+HA: T0, 1672 (SD 1068); } \\
\text { T1, } 2496 \text { (SD 1280) ( } p=0.03)\end{array}$ & $\begin{array}{l}\text { T0, } 1751 \text { (SD 767); T1, } \\
2274(\mathrm{SD} 1074)(p=0.01)\end{array}$ & $\begin{array}{l}\text { T0, } 1054 \text { (SD 525); T1, } \\
2261 \text { (SD 882); ns ( } p=0.07)\end{array}$ \\
\hline $\begin{array}{l}\text { Open/closed quotient } \\
\text { coefficient (\%) }\end{array}$ & $\begin{array}{l}\text { T0, } 75.4(11.5) ; T 1,65.8 \\
(15.3) ; \text { ns }\end{array}$ & $\begin{array}{l}\text { MSC: T0, } 72.7 \text { (SD 8.5); T1, } 67.2 \\
\text { (SD 11.1) }(p=n s) \\
\text { MSC+HA: T0, 75.2 (SD 15.5); T1, } \\
68.8 \text { (SD 20.6) ( } p=n s)\end{array}$ & $\begin{array}{l}\text { T0, } 79.3(7.5) ; \mathrm{T} 1,68.3 \\
(14.0)(p=0.05)\end{array}$ & $\begin{array}{l}\text { T0, } 57.5(9.2) ; \mathrm{T} 1,67.5 \\
(23) \\
\text { ns }\end{array}$ \\
\hline $\begin{array}{l}\text { Glottal vibration } \\
\text { parameters ratings } \\
\text { ( } 3 \text { judges) }\end{array}$ & $\begin{array}{l}10 / 16 \text { patients improved, } \\
\text { ns; or } 12 / 16 \text {, including } \\
\text { patients with improved } \\
\text { glottal closure }(p=0.039)\end{array}$ & $\begin{array}{l}\text { MSC: } 5 / 8 \text { patients improved, } 3 / 8 \\
\text { decreased (but } 2 \text { of these } \\
\text { showed improved glottal } \\
\text { closure) } \\
\text { MSC+HA: } 5 / 8 \text { patients improved, } \\
\text { 2/8 were unchanged, and 1/8 } \\
\text { decreased }\end{array}$ & $\begin{array}{l}\text { 7/11 patients improved; } \\
\text { or } 8 / 11 \text {, including } 1 \text { patient } \\
\text { with improved glottal closure }\end{array}$ & $\begin{array}{l}3 / 5 \text { patients improved; } \\
\text { or } 4 / 5 \text {, including } 1 \text { patient } \\
\text { with improved glottal closure }\end{array}$ \\
\hline
\end{tabular}



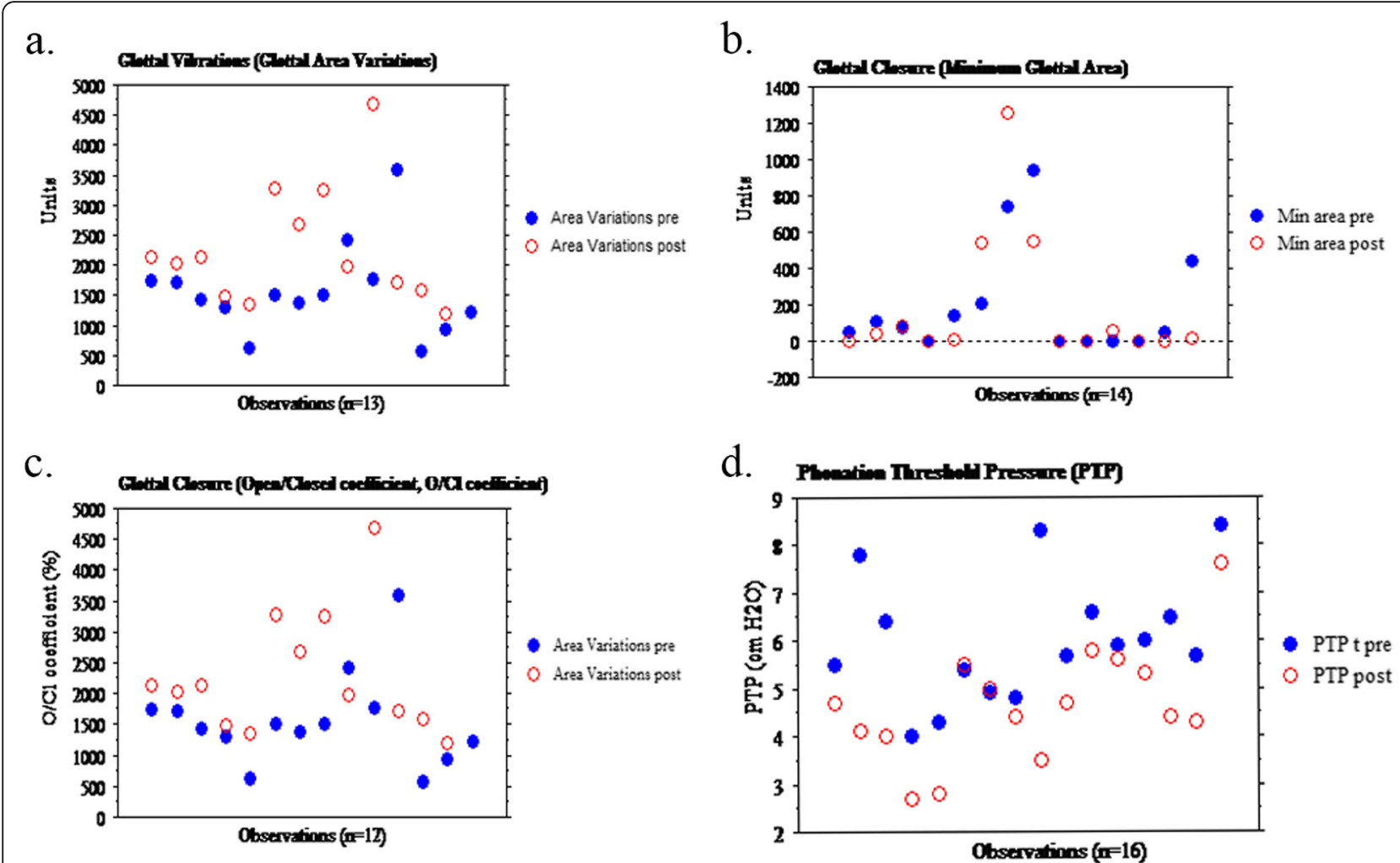

Fig. 4 Computerized analysis of vocal fold vibrations and phonation threshold pressure (PTP) results. Results presented as univariate plots pairwise before and 1 year after MSC treatment for each patient (maximum 16 observations before and after treatment). PTP results (d) for all 16 patients. Results for glottal minimum area (b) for 14 patients (2 patients were only examined with videostroboscopy and not with high-speed camera), open/closed coefficient (c) for 12 patients ( 2 were not examined with high-speed camera and for 2 patients the automatic analysis failed), glottal area variations (a) for 13 patients (2 were not examined with high-speed camera and for 1 patient the automatic analysis failed)

\section{Patient's subjective ratings, VHI}

VHI ratings (Table 2) showed a clinically significant improvement post-operative ( $>13$ points improvement) in 8 patients (for all subscales) and for remaining patients no significant change. Two patients rated their voice as normal or close to normal (with 20 points as the cutoff border between normal and deviant voice, 30).

\section{Statistical analysis and summary of vocal fold function analysis and subjective ratings}

Table 3 shows significant improvement for the maximum vibration amplitude, PTP, vibration ratings, and the VHI total score. The results were clearly better for the patients with smaller scar defects as compared to patient with larger defects. Glottal closure (open/closed quotient and closure area Tables 2 and 3) improved after treatment, however not significantly. There was no significant difference in results between the patients who received MSC injections in suspension compared to those injected with MSC+HA gel, except for the PTP which decreased significantly more for the MSC in suspension group $(p=0.006)$. Also, VHI decrease was significant in the MSC-treated group, but not in the MSC+HA group (Table 3). Higher numbers of injected MSCs did not correlate to improved VF parameters or decreased VHI ratings. Maximum vibration amplitude, open/closed quotient, PTP, and VHI improved significantly for the female patients $(p=0.04)$, whereas the male patients improved for vibration amplitude and PTP ( $p=0.02$ and $p=0.001$ respectively). There was no difference in results between the patients who did receive postoperative voice therapy $(n=11)$ or not $(n=5)$.

\section{Discussion}

To the authors' knowledge, this is the first phase I/II clinical study documenting use of autologous bone marrowderived MSC treatment in humans with VF scarring. Here we report no acute or long-term side effects or complications from MSC treatment in the evaluated 1 year after treatment. We have furthermore followed the patients with a standard clinical follow-up of 3-5 years and noted no side effects or complications. An excellent safety profile is in line with results from intravenous (IV) MSC administration $[13,14]$. We could not analyze engraftment or survival of the administered MSCs within this trial for ethical reasons, but in animal models, MSC mode of action has been demonstrated to be via a "hit and run" effect, with 
few cells persisting within the VF tissue over 1 month after injection [18-23].

VF scarring is a condition resulting in severe voice problems for which lasting effective treatment has been elusive. The patients in this study received one single MSC injection with stable results for at least 1 year post-treatment. The most significant improvement was in VF vibration capacity/elasticity. VF vibration parameters were improved for $62-75 \%$ of the patients. The majority of the patients experiencing clinical improvement reported that phonation was easier, being able to speak with less effort. This corresponds well to the improvement for the vibration parameters reflecting improved VF elasticity.

For most of the patients, the positive change in glottal parameters and in PTP became evident after 3 months (video files). This indicates an ongoing positive effect from the MSC treatment on healing with less vocal fold stiffness and tissue fibrosis. These clinical findings support our in vivo data outlining the ability of MSCs to exert longterm, indirect effects on the endogenous VF stroma, resulting in improved LP tissue architecture and healing. These findings were evidenced despite the fact that the administered cells were lost from the system within days of delivery [14, 19-23]. We administered MSC one time. It was injected during the VF operation because our previous animal experiments all showed positive effect on VF healing and function if administered in a fresh surgical wound (both in an acute damage and after resecting an established scar in the rabbit VF). Our goal was to mimic this situation. We do not know the optimal time to inject MSC, but most cells die within $24 \mathrm{~h}$ after injection in a fresh wound. We believe that early injection is optimal [19-21, 23]. Our previous study also suggests that MSCs shift early wound healing in a non-inflammatory direction [22]. We suggest that per-operative MSC injection or implantation may trigger endogenous healing responses to encourage healing of a more functional tissue repair.

Although we could not quantitatively measure the amount of scar, we suggest that the improved VF data indicates less scar tissue after MSC treatment. In 2 of our treated VFs, tissue defects were also restored (e.g., P12 Fig. 3). Any surgery of the VF LP may cause a risk for scarring, and in 4 patients, vibration ratings showed a decrease. However, for 2 of these, the remaining vibration analyses were positive with improvement for glottal closure, computerized vibration data, and PTP. The other 2 patients with decreased vibration ratings both had improved PTP, and patient 13 also improved maximum vibration amplitude, indicating improved VF elasticity. For patient 9, the oldest patient in the study, this could not be measured. The results were less favorable for the 5 patients with scar and larger defects (Table 3). This indicates that MSC injection alone does not seem to regenerate larger defects, which is in line with clinical experience and our previous results after VF resection [19-22].

VHI was significantly improved ( $>13$ points on total scale) for half of the patients, on all subscales. The remaining patients had mixed results, but no patient rated significant deterioration. As mentioned, only one VF was treated in 13 of the patients, although 9 patients had bilateral scar. The main aim of the study was to evaluate safety of MSC treatment, and the 3 patients operated bilaterally had severe or symmetrical bilateral scar. This is also the reason why we focused on VF vibrations (which can be measured on the treated VF), and no perceptual or acoustic voice analysis was reported in this study. The limited number of patients and lack of control group are limitations of the study, and it is still early to conclude the efficacy to the treatment. We have therefore planned a further study and recently received approvals from the Swedish Medical Product Agency and from the local ethical committee to start a new open phase I/II clinical trial with MSC treatment of patients with VF scarring. In this study, we chose to have the patients as their own controls and no other control group. As mentioned, the main aim of the study was safety evaluation. A control group with patients operated with scar resection only without cell treatment would risk scar healing with voice deterioration or aphonia. Also, our previous animal study where scar was resected and then treated showed increased scar healing with significant deterioration in VF viscoelasticity in the untreated scarred VFs [21].

\section{Conclusion}

In summary, this study showed an excellent safety profile in humans with VF scarring and severe voice problems treated with MSC injection. Vocal fold vibration analyses showed significant improvement in $62-75 \%$ of the patients depending on parameter analyzed. Patients with VF scar and larger defects may require alternative treatment, such as cell therapy and a suitable scaffold. Further investigation of efficacy in a larger trial is warranted where limitations with regard to defect size could be addressed to improve clinical outcome.

\section{Supplementary information}

Supplementary information accompanies this paper at https://doi.org/10. 1186/s13287-020-01632-8.

Additional file 1. File P1T0. Video file (mp4). Preoperative high speed video file for patient 1 . Showing insufficient glottal closure and decreased vocal fold (VF) vibrations on left VF.

Additional file 2. File P1T3. Video file (mp4). High speed video file for patient 1 obtained 3 months after treatment. Still insufficient glottal closure and slightly increased vibrations on left VF.

Additional file 3. File P1T12. Video file (mp4). High speed video file for patient 1 obtained 12 months after treatment. Glottal closure and clearly increased vibrations on left VF. 


\section{Abbreviations}

HA: Hyaluronan; HSL: High-speed laryngoscopy; HSS: High-Speed Studio software; LP: Lamina propria; MSC: Mesenchymal stromal cells; PTP: Phonation pressure threshold; VF: Vocal fold; VHI: Voice Handicap Index

\section{Acknowledgements}

To Fredrik Wiklund at Department of Medical Epidemiology and Biostatistics Karolinska Institutet for statistical advice. To Lindsay Davies, Department of Laboratory Medicine, Karolinska Institutet, for language revision and editing of the manuscript. To Mattias Krakau, Department of Otorhinolaryngology, Karolinska University Hospital, for figure drawings. To Hans Larsson (deceased), formerly at Karolinska Institutet. Department of Logopedics, who designed the computer programs for high-speed video recording and analysis (High-Speed Studio).

\section{Authors' contributions}

SH planned the study, performed surgery, analyzed and interpreted all the patient data, and was a major contributor in writing the manuscript. SR took part in the planning of the study, performed the delivery of the MSC, assisted in the data collection and analysis, and was a major contributor in writing the manuscript. EM assisted in surgery and in data collection, and analysis of video recordings. KLB planned the study, harvested the MSCs, and was a major contributor in writing the manuscript. The authors read and approved the final manuscript.

\section{Funding}

The Swedish Research Council (K2011-X-20742-04-6), Stockholm County Council (ALF Medicin, 20110152), Swedish Foundation for Strategic Research, IKE-2014-00354), Laryngfonden (50/14), Karolinska Institutet

\section{Availability of data and materials}

The datasets generated and/or analyzed during the current study are not publicly available due [Dataare kept protected following the routines of the Institution at Karolinska Institutet], but are available from the corresponding author on reasonable request.

\section{Ethics approval and consent to participate}

Ethical permissions (DNR 2010/1650 and DNR 2014/51432) were received from the Stockholm regional ethical review committee. Patients provided written informed consent before the procedure. The MSC expansion procedure was accredited by the Swedish National Board of Health and Welfare (952/2009, 6.3.3-8874/2011, 6.1.3-9791/2013, 6.1.3-16411/201).

\section{Consent for publication}

The patients gave consent for publication of the data (made unidentifiable)

\section{Competing interests}

The authors declare that they have no competing interests.

\section{Author details}

${ }^{1}$ Department of Clinical Sciences and Intervention, Karolinska Institutet, Stockholm, Sweden. ${ }^{2}$ Department of Otorhinolaryngology, Karolinska University Hospital Huddinge, S-141 86 Stockholm, Sweden. ${ }^{3}$ Department of Laboratory Medicine, Karolinska Institutet, Huddinge, Sweden. ${ }^{4}$ Patient Area Cell Therapies and Allogeneic Stem Cell Transplantation, Karolinska University Hospital Huddinge, Stockholm, Sweden.

Received: 14 January 2020 Revised: 24 February 2020 Accepted: 2 March 2020 Published online: 20 March 2020

\section{References}

1. Ramig LO, Verdolini K. Treatment efficacy: voice disorders. J Speech Lang Hear Res. 1998:41:101-16

2. Cohen SM, Kim J, Roy N, Asche C, Courey MS. Direct health care costs of laryngeal diseases and disorders. Laryngoscope. 2012;122:1582-8.

3. Coyle SM, Weinrich BD, Stemple JC. Shifts in relative prevalence in laryngeal pathology in a treatment-seeking population. J Voice. 2001;15:424-40.

4. Hansen JK, Thibeault SL. Current understanding and review of the literature: vocal fold scarring. J Voice. 2006;20:110-20.

5. Cantarella G, Mazzola RF, Gaffuri M, lofrida E, Biondetti P, Forzenigo LV, Pignataro L, Torretta S. Structural fat grafting to improve outcomes of vocal folds' fat augmentation: long-term results. Otolaryngol Head Neck Surg. 2018;158(1):135-43. https://doi.org/10.1177/0194599817739256 Epub 2017 Nov 21.

6. Chhetri DK, Mendelsohn AH. Hyaluronic acid for the treatment of vocal fold scars. Curr Opin Otolaryngol Head Neck Surg. 2010;18(6):498-502. https:// doi.org/10.1097/MOO.0b013e32833f85d1.

7. Hirano S, Kawamoto A, Tateya I, Mizuta M, Kishimoto Y, Hiwatashi N, Kawai Y, Tsuji T, Suzuki R, Kaneko M, Naito Y, Kagimura T, Nakamura T, Kanemaru SI. J Tissue Eng Regen Med. 2018; 12(4):1031-1038. doi: https://doi.org/10. 1002/term.2603. Epub 2017 Dec 25.PMID: 29084372.

8. Ban MJ, Park KN, Kim HK, Lee SW. The efficacy of fibroblast growth factor for the treatment of chronic vocal fold scarring: from animal model to clinical application. Clin Exp Otolaryngol. 2017;10(4):349-56. https://doi.org/ 10.21053/ceo.2016.00941 Epub 2016 Sep 27.

9. Chhetri DK, Berke GS. Injection of cultured autologous fibroblasts for human vocal fold scars. Laryngoscope. 2011;121:785-92.

10. Le Blanc K, Mougiakakos D. Multipotent mesenchymal stromal cells and the innate immune system. Nat Rev Immunol. 2012;12:383-96. https://doi.org/ 10.1038/nri3209.

11. Bernardo ME, Fibbe BE. Mesenchymal stromal cells: sensors and switchers of inflammation. Cell Stem Cell. 2013:13(4):392-402. https://doi.org/10.1016/j. stem.2013.09.006.

12. Wilson JG, Liu KD, Zhuo H. Caballero, M. McMillan, X. Fang, K. Cosgrove, R. Vojnik, C.S. Calfee, J.W. Lee, A.J. Rogers, J. Levitt, J. Wiener-Kronish, E.K. Baijwa, A. Leavitt, D. McKenna, B.T. Thompson, M.A. Matthay. Mesenchymal stem (stromal) cells for treatment of ARDS: a phase 1 clinical study Lancet Respir Med. 2015; 3(1):24-32. doi: https://doi.org/10.1016/S22132600(14)70291-7. Epub 2014 Dec 17.

13. Le Blanc K, Frassoni F, Ball L, Locatelli F, Roelofs H, Lewis I, Lanino E, Sundberg B, Bernardo ME, Remberger M, Dini G, Egeler M, Bacigalupo A, Fibbe W, Ringdén $\mathrm{O}$. Mesenchymal stem cells for treatment of steroid-resistant, severe, acute graft-versus-host disease: a phase II study. Lancet. 2008;371:1579-86.

14. von Bahr L, Batsis I, Moll G, Hägg M, Szakos A, Sundberg B, Uzunel M, Ringden O, Le Blanc K. Analysis of tissues following mesenchymal stromal cell therapy in humans indicates limited long-term engraftment and no ectopic tissue formation. Stem Cells. 2012;30(7):1575-8. https://doi.org/10. 1002/stem.1118

15. Tolar J, Le Blanc K, Keating A, Blazar B. Hitting the right spot with mesenchymal stromal cells. Stem Cells. 2010;28:1446-55.

16. Kanemaru S, Nakamura T, Yamashita M, Magrufov TK, Tamaki H, Tamura Y, Iguchi F, Kim TS, Kishimoto M, Omori K, Ito J. Destiny of autologous bone marrow-derived stromal cells implanted in the vocal fold. Ann Otol Rhinol Laryngol. 2005;114:907-12.

17. Valeri A, Vassiliki K, Irini M, Nikolaos P, Karampela E, Apostolos P. Adipose-derived mesenchymal stem cells in the regeneration of vocal folds: a study on a chronic vocal fold scar. Stem Cells Int Volume. 2016; Article ID 9010279, 12 pages.

18. Hiwatashi N, Hirano S, Suzuki R, Kawai Y, Mizuta M, Kishimoto Y, Tateya I, Kanemaru SI, Nakamura T, Dezawa M, Ito J. Comparison of ASCs and BMSCS combined with atelocollagen for vocal fold scar regeneration. Laryngoscope. 2015. https://doi.org/10.1002/lary.25667 [Epub ahead of print].

19. Hertegård S, Cedervall J, Svensson B, Forsgren K, Maurer FHJ, Vidovska D, Olivius P, Ährlund-Richter L, Le Blanc K. Viscoelastic and histological properties in scarred rabbit vocal folds after mesenchymal stem cell injection. Laryngoscope. 2006;116:1248-54.

20. Svensson B, Nagubothu RS, Cedervall J, Le Blanc K, Ährlund-Richter L, Tolf A Hertegård S. Injection of human mesenchymal stem cells improve healing of scarred vocal folds - an analysis using a xenograft model of rabbits. Laryngoscope. 2010;120:1370-5.

21. Svensson B, Nagubothu RS, Cedervall J, Le Blanc K, Maurer FHJ, ÄhrlundRichter L, Tolf A, Hertegård S. Injection of human mesenchymal stem cells improve healing of vocal folds after scar excision- a xenograft analysis. Laryngoscope. 2011;121(10):2185-90.

22. Nagubothu SR, Sugars RV, Tudzarovski N, Törnqvist Andrén A, Bottai M, Davies LC, Hertegård S, Le Blanc K. Mesenchymal stromal cells modulate tissue repair responses within the injured vocal fold. Laryngoscope. 2019. https://doi.org/10.1002/lary.27885 [Epub ahead of print].

23. Hertegård S, Nagubothu SR, Malmström E, Ström C, Tolf A, Davies LC, Blanc $K^{*}$. Hyaluronan hydrogels offer a safe and efficient means for the local delivery of mesenchymal stromal cells to the injured vocal fold. *shared senior author. Stem Cells Dev. 2019; doi: https://doi.org/10.1089/scd.2019. 0102. [Epub ahead of print]. 
24. Mattei A, Magalon J, Bertrand B, Grimaud F, Revis J, Velier M, Veran J, Dessi P, Sabatier F, Giovanni A. Autologous adipose-derived stromal vascular fraction and scarred vocal folds: first clinical case report. Stem Cell Res Ther. 2018;9(1):202. https://doi.org/10.1186/s13287-018-0842-0.

25. Le Blanc K, Tammik L, Sundberg B, Haynesworth SE, Ringden O.

Mesenchymal stem cells inhibit and stimulate mixed lymphocyte cultures and mitogenic responses independently of the major histocompatibility complex. Scand J Immunol. 2003;57(1):11-20.

26. Dominici M, Le Blanc K, Mueller I, Slaper-Cortenbach FM, Krause D, Deans R, Keating A, Prokop DJ, Horwitz E. Minimal criteria for defining multipotent mesenchymal stromal cells. The International Society for Cellular Therapy position statement. Cytotherapy. 2006;8(4):315-7.

27. Bergman K, Engstrand T, Hilborn J, Ossipov D, Piskounova S, Bowden T. Injectable cell-free template for bone-tissue formation. J Biomed Mater Res A. 2009;91(4):1111-8. https://doi.org/10.1002/jbm.a.32289.

28. Hertegård S, Larssson H. A portable high speed camera system for vocal fold examinations. J Voice. 2016;28(6):681-7. https://doi.org/10.1016/j.jvoice. 2014.04.002 Epub 2014 Jul 5.

29. Titze IR. Phonation pressure threshold: a missing link in glottal aerodynamics. J Acoust Soc Am. 1992;91(5):2926-35.

30. Ohlsson AC, Dotevall H. Voice handicap index in Swedish. Log Phon Voc. 2009;34:60-6.

\section{Publisher's Note}

Springer Nature remains neutral with regard to jurisdictional claims in published maps and institutional affiliations.

Ready to submit your research? Choose BMC and benefit from:

- fast, convenient online submission

- thorough peer review by experienced researchers in your field

- rapid publication on acceptance

- support for research data, including large and complex data types

- gold Open Access which fosters wider collaboration and increased citations

- maximum visibility for your research: over $100 \mathrm{M}$ website views per year

At BMC, research is always in progress.

Learn more biomedcentral.com/submissions 